\title{
Commentary: From bioprosthetic tissue degeneration to regeneration: A new surgical horizon in the era of regenerative medicine
}

\author{
Igor E. Konstantinov, MD, PhD, FRACS, ${ }^{\mathrm{a}, \mathrm{b}, \mathrm{c}, \mathrm{d}}$ Tyson A. Fricke, MBBS, BMedSci, ${ }^{\mathrm{a}, \mathrm{b}, \mathrm{c}}$
} Yaroslav Ivanov, MD, ${ }^{\mathrm{a}}$ and Enzo Porrello, $\mathrm{PhD}^{\mathrm{c}, \mathrm{d}, \mathrm{e}}$

\footnotetext{
From the ${ }^{\mathrm{a} D e p a r t m e n t ~ o f ~ C a r d i o t h o r a c i c ~ S u r g e r y, ~ T h e ~ R o y a l ~ C h i l d r e n ' s ~ H o s p i t a l, ~ M e l b o u r n e, ~ A u s t r a l i a ; ~}{ }^{\mathrm{b}}$ Department of Paediatrics, The University of Melbourne, Melbourne, Australia; the ${ }^{c}$ Murdoch Children's Research Institute, Melbourne, Australia; ${ }^{\mathrm{d}}$ Melbourne Children's Centre for Cardiovascular Genomics and Regenerative Medicine, Melbourne, Australia; and ${ }^{\mathrm{e} D e p a r t m e n t ~ o f ~ P h y s i o l o g y, ~ T h e ~ U n i v e r s i t y ~ o f ~ M e l b o u r n e, ~ M e l b o u r n e, ~}$ Australia.

Disclosures: Authors have nothing to disclose with regard to commercial support.

Received for publication Jan 21, 2019; accepted for publication Jan 22, 2019; available ahead of print Feb 26, 2019.

Address for reprints: Igor E. Konstantinov, MD, PhD, FRACS, Royal Children's Hospital, Flemington Rd, Parkville, Victoria 3052, Australia (E-mail: igor.konstantinov@ rch.org.au).

J Thorac Cardiovasc Surg 2019;158:742-3 $0022-5223 / \$ 36.00$

Crown Copyright $\odot 2019$ Published by Elsevier Inc. on behalf of The American Association for Thoracic Surgery https://doi.org/10.1016/j.jtcvs.2019.01.084
}

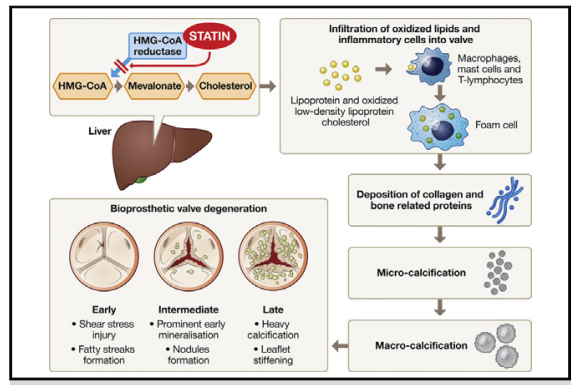

Statins and macrophages in bioprosthetic valve degeneration.

Central Message

Statins may decrease calcification of biologic tissue valve prostheses. Macrophages may play a key role in biologic valvular tissue longevity.

See Article page 731
Just more than 100 years has passed since the very first studies showing the link between high-fat diet, increased cholesterol level, and development of atherosclerotic damage to cardiovascular the system. ${ }^{1,2}$ Simplistically, it appears logical that controlling cholesterol at a normal level through various lipid-lowering strategies, including administration of statins, would reduce atherosclerotic degeneration. The statins are commonly used as a part of lipid-lowering therapy acting as a 3-hydroxy-3-methylglutaryl-coenzyme A reductase inhibitor that is the ratelimiting enzyme in the synthesis of cholesterol (Figure 1). Could the same strategies by used to prevent bioprosthetic valve degeneration? Although the beneficial effect of statins to slow the progress of atherosclerosis has been demonstrated, the use of statins to prevent deterioration and calcification of bioprosthetic tissues remains controversial. ${ }^{3,4}$

A very interesting and thought-provoking article by Lee and colleagues ${ }^{5}$ on the effect of statin treatment on bioprosthetic tissue calcification in rats is published in this issue of the Journal. Twenty rats were fed a high-fat diet for 1 month and then randomly assigned to receive either statin therapy with a high-fat diet or a high-fat diet alone. Tissues of 4 types of bioprosthetic valves were implanted subcutaneously and excised 12 weeks later. Lee and colleagues ${ }^{5}$ found that rats treated with a statin had less calcification and a lower inflammatory infiltrate affecting the cusps of the excised valve.

It is tempting to take a closer look at the mechanism of the atherosclerotic damage. Macrophages constantly survey both native and implanted biologic tissues. Macrophages play a crucial role in the clearance of cellular debris and maintaining tissue homeostasis. Fatty streak formation occurs in areas of high shear stress. Macrophages infiltrating fatty streaks engulf lipoproteins and cholesterol in an attempt to clear the tissue of excessive lipoprotein deposits. Overwhelmed by engulfed lipoproteins, macrophages become foam cells that are incapable of effective clearance of debris and, in fact, contribute to tissue degeneration and calcification (Figure 1). Although the role of macrophages in atherosclerosis has been recognized for almost a century, the essential role of macrophages in tissue regeneration has only recently become apparent. ${ }^{6}$

Cellular senescence has recently been linked to the promotion of age-related pathologies and a decline in tissue regenerative capacity. Interestingly, it was previously demonstrated that senescent cells accumulate in patients with chronic inflammation of the pericardium. ${ }^{7}$ Senescent cells produced more collagen, attracted more white blood cells, and deposited more calcium. ${ }^{7}$ This may in part explain the fact that pericardial bioprostheses are particularly vulnerable to calcification. Effective immune clearance of senescent cells by macrophages could be important in both prevention of structural deterioration and tissue regeneration. ${ }^{8}$ For example, salamanders have a remarkable ability to regenerate complex tissues, including 


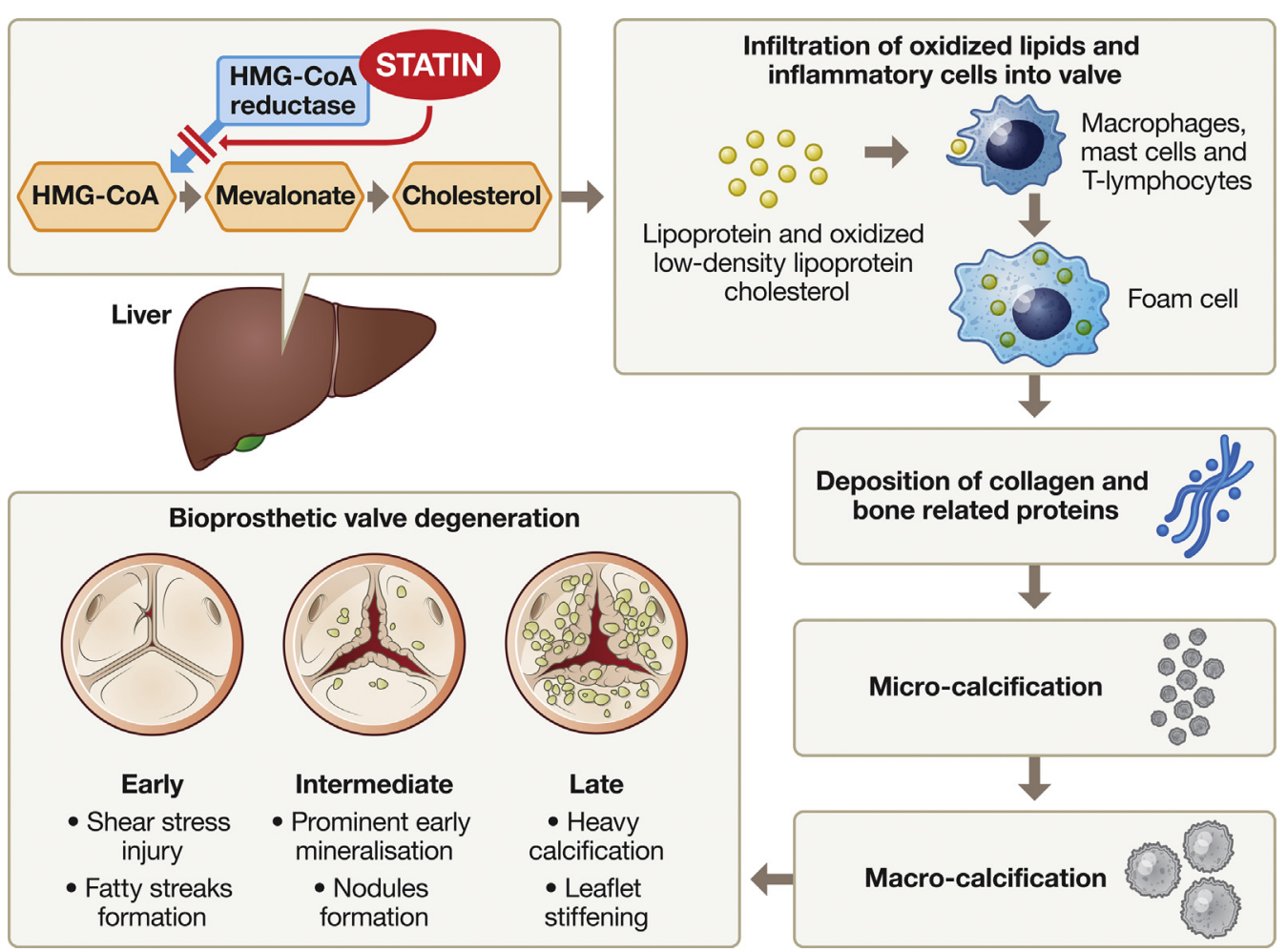

FIGURE 1. Schematic pathways of statins' lipid lowering strategy to reduce bioprosthetic valve degeneration. HMG-CoA, 3-hydroxy-3-methylglutarylcoenzyme A.

heart tissues. Salamanders also have a superbly efficient mechanism of eliminating senescent cells through macrophage-dependent immune clearance. ${ }^{9}$ Could such a regenerative pathway be emulated to prevent structural deterioration of implanted biologic tissues in patients? The use of a multifaceted strategy to improve macrophage-dependent clearance of metabolic and cellular debris may dramatically improve longevity of bioprosthetic heart valves.

\section{References}

1. Konstantinov IE, Mejevoi N, Anichkov NM. Nikolai N. Anichkov and his theory of atherosclerosis. Tex Heart Inst J. 2006;33:417-23.

2. Konstantinov IE, Jankovic GM. Alexander I. Ignatowski: a pioneer in the study of atherosclerosis. Tex Heart Inst J. 2013;40:246-9.
3. Gilmanov D, Bevilacqua S, Mazzone A, Glauber M. Do statins slow the process of calcification of aortic tissue valves? Interact Cardiovasc Thorac Surg. 2010;11: 297-301.

4. Farivar RS, Cohn LH. Hypercholesterolemia is a risk factor for bioprosthetic valve calcification and explantation. J Thorac Cardiovasc Surg. 2003;126:969-75.

5. Lee S, Kim D-H, Youn Y-N, Joo HC, Yoo K-J, Lee SH. Rosuvastatin attenuates bioprosthetic heart valve calcification. J Thorac Cardiovasc Surg. 2019;158: 731-41.e1.

6. Aurora AB, Porrello ER, Tan W, Mahmoud AI, Hill JA, Bassel-Duby R, et al Macrophages are required for neonatal heart regeneration. J Clin Invest. 2014; 124:1382-92.

7. Han L, Li X, Zhang G, Xu Z, Gong D, Lu F, et al. Pericardial interstitial cel senescence responsible for pericardial structural remodeling in idiopathic and postsurgical constrictive pericarditis. J Thorac Cardiovasc Surg. 2017;154:966-75.e4.

8. Konstantinov IE, Ye XT, Fricke TA. From cellular senescence to regeneration: a quest for the holy grail for the next generation of surgeons? J Thorac Cardiovasc Surg. 2017;154:953-4

9. Yun MH, Davaapil H, Brockes JP. Recurrent turnover of senescent cells during regeneration of a complex structure. Elife. 2015;4:e05505. 